\title{
Applying a consulting system in the management of construction companies' interactions
}

\author{
Larisa Selyutina $^{1}$, Elena Pesotskaya $^{2, *}$, Maria Ivanova $^{3}$, and Tatiana Maleeva ${ }^{4}$ \\ ${ }^{1}$ Emperor Alexander I St. Petersburg State Transport University, 190031, Moskovsky pr., 9, St. \\ Petersburg, Russia \\ ${ }^{2}$ Saint-Petersburg State University of Economics, 191023, Sadovaya str., 21, St. Petersburg, Russia \\ ${ }^{3}$ Saint Petersburg State University of Civil Aviation, 196210, street of Pilots, 38, St.Petersburg, \\ Russia \\ ${ }^{4}$ Pushkin Leningrad State University, 196605, St. Petersburg sh., Pushkin, 10, St. Petersburg, Russia
}

\begin{abstract}
The article reveals the interaction system features of construction companies, substantiates the need to introduce special management means into the organizational and management practice of construction companies, which include management consulting. The features of management consulting, its methodology and methods are considered. The author's approach to the formation of managerial decisions in the system of interactions between construction companies, focused on the implementation of the principle of joining internal and external consultants' efforts within the framework of combined consulting, is stated. It is shown that combined consulting acts as universal mean that provides a full suite of services in management, creating preconditions for the successful implementation of the principles of the concept of interaction in the management of construction companies, and is the most important factor that activates the construction companies' interaction with the subjects of the regional investment and construction market.
\end{abstract}

\section{Introduction}

Under modern conditions of the ongoing reform process across all sectors and realms of the Russian economy, the improvement of the construction business management methods is important, aimed at increasing the level of adaptability of construction companies to the dynamically developing competitive environment $[1,2]$. It must be emphasized that the adoption and implementation of management decisions in the field of rationalization of interactions (for example, the transition to new forms of cooperation between actors operating in the investment and construction market) can be legitimately identified as a complex process that requires significant innovative experience and the volume of innovative potential of the enterprise, and that most of these decisions are quite appropriate

*Corresponding author: epes2@mail.ru 
to develop through the involvement of professional knowledge and experience of consultants [3].

Taking the above mentioned into consideration, it is advisable to take the following hypothesis as a basis: a systematic approach should underpin the process of strategic decision making on managing the interactions between construction companies, firstly, it assumes the full involvement of all the available advantages of interaction with entrepreneurial business, and secondly, aimed at intensive development of interaction in order to identify new, additional opportunities within the issues under investigation of partnership and interaction. In this connexion, the goal of the research carried out in this article is the justification of necessity and possibility of attracting means of consulting to fulfill the tasks set before construction companies in the process of their interaction under the conditions of complicating competitive environment.

\section{Materials and Methods}

In this research it is highlighted the thesis of the concepts of the interaction theory which are the conceptual and categorical framework that guarantees the reality of an adequate and enough impartial, objectively suitable description of the features, type and motives of interactions between business entities within a competitive market environment. The category of interactions between business partners in the construction market should be recognized as predominant in the interpretation of the economic nature and essence of competition under current conditions. The positive role of economic rivalry between participants in the market economy is manifested in the quality of the formation and improvement of competitive interactions and the building up of competitive advantages at all levels and in the spheres of economic activities.

Interaction as a process of direct and indirect affections of business entities to each other establishes a concrete basis for the development and preservation of the competitive advantages achieved by the company, which can be manifested in a peculiar way as a general category, on the one hand, and as the local characteristic of a specific feature that favorably distinguishes a particular enterprise from other similar entities in the market, on the other hand. During the last decades, the construction sector as a complex economic system has undergone a number of substantial alterations associated with the acceleration of scientific and technological progress, the need to introduce innovative management methods.

The use of the principle of market adaptation in the process of interactions between entities orientates construction companies to improve the organization of production and management within the framework of strategic and tactical actions. Moreover, the competitive struggle as a distinctive feature of the market economy is not weakening under current conditions [4]. The measures aimed at attracting special management facilities to the managerial and workplace problems solving, comprising management consulting, helps enterprises to function and develop under such conditions.

\section{Results and Discussion}

The problems of management consulting are covered in many scientific works of domestic and foreign experts: E. Pesotskaya, L. Selyutina, L. Bazarova, V. Biswas, D. Twitchell and others. Their interpretations of management consulting are somewhat different from each other, but there are no fundamental differences between them. Based on the results of the analysis of these interpretations, it seems appropriate to take as a basis the definition formulated in the work [5]. 
A characteristic feature of modern research on the methodology of consulting and methods of its implementation is the predominant focus on management consulting [6], which is probably due to its widespread use in practice. To confirm this thesis, one can cite the classification of consulting services proposed by D. Litvin [7]. It should be noted that, in fact, all of the types of consulting presented in this classification cover many aspects of the management process, which, by the way, made it possible to identify consulting as an activity with a multidisciplinary specialization. Of interest is the classification of consulting proposed by L. Bazarova, also focusing on management consulting [8]. In the system of interaction between construction companies, of course, all types of management consulting can be used. Expert consulting is widely applicable, it has versatility and is suitable for solving any problems. The typology proposed in [9] generalizes a number of typological criteria and highlights the most significant of them (Figure). This method of structuring represents systematic assessments that are useful for various fields of activity, including the construction sector.

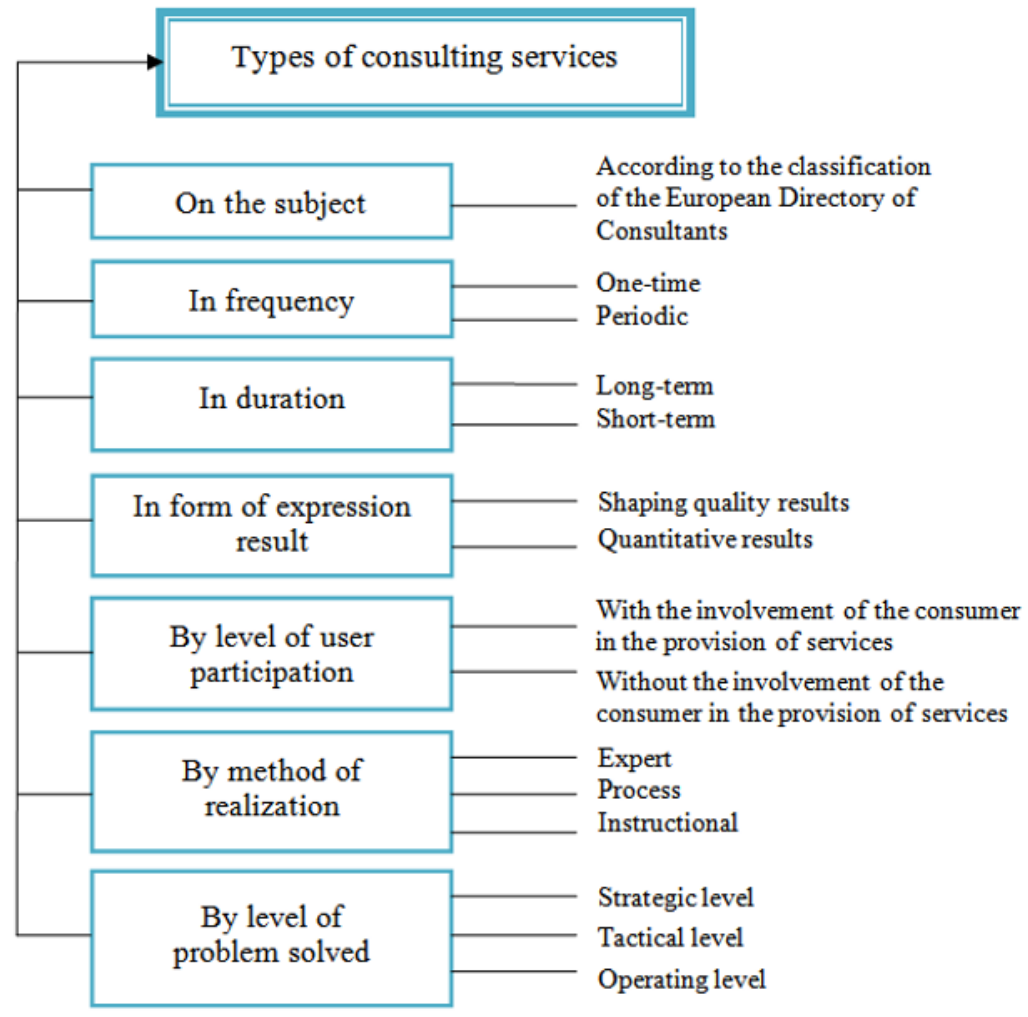

Fig. 1. Types of management consulting services.

In attempts to adapt these features to the specifics of the construction industry, it is important to note that articulation in one system (a subsystem of the control system) will probably require the use of special organizational techniques. The basis for the formation of such organizational techniques should be the separation of the management consulting function and the creation of appropriate organizational structures.

Organizational support of management consulting (in its theoretical models) includes two types of it:

- External consulting;

- Internal consulting. 
External consultants include invited experts, who are always assigned specific, welldefined tasks. Such consultants are invited to design and implement specific projects or to the rationalization of processes. The project-based approach is predominantly used. The consultants can be invited on any of the project stages and for projects of any scale. When developing large projects, the involvement of consultants (working individually or as part of a group) is a common practice [10]. Moreover, its success directly depends on the correct choice of consultants as representatives of the consulting services market that has developed in Russia and its regions. Internal consultants are staff members of an organization whose experience and knowledge determine their authority and leadership (often informal) positions. Specialists with the largest volume of necessary information should also be involved as internal consultants.

Practice shows that in most cases the leadership of organizations seeks to attract external consultants from among recognized authorities, that is fully justified. The management personnel of organizations, as a rule, cannot abstract the mind from internal organizational problems and contradictions, which means that they can objectively assess neither the existing problems, nor the possible ways to solve them. External specialists are devoid of this disadvantage, and their independence becomes the key factor in achieving the justification of the decisions made. In the system of organizing the interaction process (in the economic and managerial interpretation), the situation is somewhat different. Connections within organization in this system are weaker, and the information flow is sufficiently complete. Essentially, each of the organizations included in the system can provide professional consultants for other such organizations, who will be external to them. At the same time, the interest of the consultants in the results of the activities of the consulted organization will be ensured (to a large extent) and their independence will be preserved, although not completely. Intra-organizational ties in this system are weaker, and the information flow is quite complete. Essentially, each of the organizations included in the system can provide specialists-consultants for other such organizations, who will be external to them. At the same time, the interest of the consultants in the results of the activities of the consulted organization will be ensured (to a large extent) and their independence will be preserved, although not completely.

The use of external consultants, for all their usefulness, is not free from shortcomings.

First, it is obvious that they have no direct interest in the success of the organization of interactions, and in the absence of a clearly fixed connection between goals and interests, it is practically impossible to ensure the achievement of the latter [11].

Second, the involvement of external consultants in the management of the interaction system is always associated with the dissemination of internal information to the external environment. In the organization's internal processes of a construction company, not only positive, but also negative information is created that one would not want to broadcast. Negative information, for all its necessary for the analysis and selection of certain response measures, should be accumulated in the internal environment, and its spread to the external environment must be prevented [12].

Thirdly, external consultants, despite their efforts, cannot characterize in a fairly complete manner all the elements of the internal environment of the interaction system organization of the construction company. Only formalized information is available to them. But organization's internal processes are never fully formalized. Non-formalized, accurately hidden processes are also emerging, interpersonal communications (with all their uncertainty) are actively manifesting themselves, influence groups are formed that do not have fixed boundaries etc. [13]. Non-formalized processes, as a rule, are represented at insufficiently understandable multitude in construction companies, but their impact is always felt. The task of the management system in such a case is reduced to the study and compensation of non-formalized processes that give rise to the organization's internal 
problems, and sometimes leading to the destruction of the organization and, at the same time, to support processes that are capable in implicit form to stimulate development.

The foregoing forms the basis for the formation of the following proposal: when developing and implementing a system of interaction, it is advisable to follow the principle of combining the efforts of internal and external consultants in the framework of combined consulting [14]. Combined consulting, as a phenomenon, has clearly manifested itself in Russian practice. In the economic literature, it has not yet received sufficient reflection. However, its main features can be characterized quite clearly if we rely on the typology of consulting as a producer of consulting services.

\section{Conclusions}

The aforesaid allows us to characterize management consulting in construction business organizations as the symbiosis of positive and negative qualities. However the influence of negative qualities can be reduced through the use of special type of consulting, so called a combined consulting. Combined consulting as an organizational and a managerial method in the fulfillment of consultation exercise has the following feature - it is intended to combine the efforts of internal and external consultants. Combined consulting is among the phenomena are initiated by practical experience. It is still insufficiently provided with theoretical and methodological substantiation. But some theoretical and methodological research studies have been carried out and, based on their results, it is possible to identify combined consulting as a producer of services special type.

\section{References}

1. B. Kuznetsov et al., E3S Web of Conferences 263, 05017 (2021)

2. E. Trushkovskaya et al., IOP Conf Ser: Mater. Sci. Eng. 753, 032044 (2020)

3. T. V. Maleeva et al., IOP Conf. Ser.: Mater. Sci. Eng. 687, 044002 (2019)

4. L.G. Selyutina, Methodological problems of optimization of the structure of the housing stock and housing in a major city in modem conditions: Diss. Doc. Econ. of Sciences (2002)

5. O. Egorova et al., IOP Conf. Ser.: Mater. Sci. Eng. 698, 077029 (2019)

6. S. Biswas, D. Twitchell, Management Consulting: A Complete Guide to the Industry. (2004)

7. D. V. Litvin, Russian banks in the consulting services market: Dissertation (2000)

8. L. A. Bazarova, Socio-technological and situational variables of management consulting. Dissertation, Belgorod State University (2002)

9. E. Pesotskaya et al., IOP Conf Ser: Mater. Sci. Eng. 962, 022082 (2020)

10. A. H. Hakimov et al., IOP Conf Ser: Earth Environ. Sci. 751, 012173 (2021)

11. M. Ivanova et al., E3S Web of Conf 281, 08001 (2021)

12. E. Rybnov et al., E3S Web of Conferences 217, 11010 (2020)

13. E. Pesotskaya et al., IOP Conf Ser: Mater. Sci. Eng. 698, 077030 (2019)

14. M. Ivanova et al., E3S Web of Conferences 291, 05010 (2021) 